\title{
Effect of Macrochelidae (Acarina: Mesostigmata) on House Fly Production From Dairy Cattle Manure ${ }^{1}$
}

\author{
Richard C. Axteld, ${ }^{2}$ Cornell University, Ithaca, N. Y.
}

\begin{abstract}
Caged areas of intact calf pen manure with the mite population undisturbed produced $61 \%$ to $67 \%$ fewer house flies (Musca domestica Linnaeus) than did areas with the mites destroyed by Kelthane ${ }^{(1,1-b i s(p-c h l o r o p h e n y l)-2,2,2-t r i c h l o r o e t h a n o l) ~}$ when $20,000 \mathrm{fly}$ eggs were added to each area. Outdoor piles of dairy cattle manure with the mite population undisturbed produced $31 \%$ to $45 \%$ fewer house flies than did piles with the mites destroyed by Kelthane, when 50,000 fly eggs were added to each pile. Indoor caged piles of fresh dairy cattle manure to which 20,000 house fly eggs were added produced $94 \%$ fewer flies when 200 Macrocheles muscaedomesticae (Scopoli) and 200 Glyptho-

laspis confusa (Foà) were added than did piles to which no mites were added. Similar reductions in fly production in the presence of the mites resulted when 20,000 and 60,000 eggs and fresh manure were added to the piles 3 weeks later. Addition of 60,000 eggs to indoor caged piles of fresh dairy cattle manure, to which were added $200 \mathrm{M}$. muscaedomesticae and $200 \mathrm{G}$. confusa, resulted in $83 \%$ fewer house flies than were produced from piles with no mites. The reductions in numbers of house flies by the mites were large compared to the actual fly production from manure but were small compared to the potential production of flies from the numbers of eggs added.
\end{abstract}

Mites are commonly observed in domestic animal manure which is suitable for house fly (Musca domestica Linnaeus) breeding. Frequently a majority of these mites are Macrochelidae. The following species have been collected from manure in New York State: Glyptholaspis confusa (Foà), Macrocheles muscaedomesticae (Scopoli), M. subbadius (Berlese), M. robustulus (Berlese), M. medarius (Berlese), M. glaber (Müller), and M. matrius (Hull). The occurrence of the first five species was reported by Axtell (1961) along with the rates of destruction of house fly eggs and first-instar larvae by the first four species. The last two species have not been previously reported in the United States.

The significance of these macrochelids in controlling house flies was suggested by the report of Pereira and de Castro (1945) that all but the first instar of M. muscaedomesticae fed on house fly eggs. The same workers (1947) established that the adult female mites were phoretic, not parasitic, on the adult house fly and reproduced by arrhenotokous parthenogenesis. Filipponi (1955) re-evaluated the nature of the association between $M$. muscaedomesticae and the house fly and reached the same conclusions. He also found the mites attacked mostly eggs and first-instar house fly larvae; house fly larvae in the second and third instars were not usually consumed by the mites. Rodriguez and Wade (1961) found that substrate differences influenced the rates of reproduction and predation on house fly eggs under laboratory conditions. Wade and Rodriguez (1961) reported a detailed life history of $M$. muscaedomesticae.

It has been repeatedly shown under laboratory conditions that macrochelids kill house fly eggs and first-instar larvae by piercing the chorion or integument and sucking out the contents. Evidence of predation by macrochelids on the house fly under field conditions has not been reported. Therefore, experiments were conducted to determine the extent of predation on the house fly by existing and introduced mites in dairy cattle manure under conditions approximating normal environments, including intact calf pen manure, outdoor manure piles, and indoor manure piles.

Materials and Methods.-Evaluation of the predation by mites on the house fly under field conditions was conducted in the vicinity of Ithaca, New York, during the summers of 1960 and 1961 , with (1) existing mite populations and (2) introduced mite populations.

The fly eggs were introduced, the number being determined by extrapolation from a counted aliquot. The mean of the counts for five 5 -ml. aliquots was used to calculate the number of eggs per $\mathrm{ml}$. in a water-eggs mixture agitated by a magnetic stirrer. The number of $\mathrm{ml}$. of watereggs mixture necessary to give the desired number of eggs was pipetted into screw-cap jars used to carry the eggs to the locations of the experiments. The mean number of eggs per $\mathrm{ml}$. determined in this way was reproducible. Eight such successive determinations gave a mean of 58.2 eggs per ml. with a standard deviation of 0.79 and a range of $57.1-59.7$.

The eggs were held in water under agitation for 20 to 40 minutes. This had no serious effect on fly production from

\footnotetext{
${ }^{1}$ From a thesis submitted in June 1962 to the Graduate School, Cornell University, in partial fulfillment of requirements for the degree of Doctor of Philosophy. This investigation was carried out during the tenure of a Predoctoral Fellowship from the National Institutes of Health, United States Public Health Service. Accepted for publication August 20, 1962.

2 Present address: Department of Entomology, North Carolina State College,
} Raleigh. The advice of J. G. Matthysee is gratefully acknowledged. 
the eggs. For example, after agitating a batch of eggs for 10,20 , and 30 minutes, $80 \%, 79 \%$, and $81 \%$, respectively, produced adult flies as compared to $78 \%$ after 1 hour, $70 \%$ after 2 hours, and $66 \%$ after 3 hours.

All house fly eggs were obtained from flies reared from egg to adult in CSMA (Chemical Specialties Manufacturers Association) medium (Ralston-Purina Co.) with yeast added. Adult flies were held in screen cages $(45 \mathrm{~cm}$. $\times 60 \mathrm{~cm} . \times 45 \mathrm{~cm}$.) and fed milk. Eggs were collected on cellucotton dampened with milk.

Studies with Existing Mite Populations.-Experiments on predation by naturally occurring mite populations were conducted on (1) intact calf pen manure and (2) outdoor piles of manure. Fly production was determined by the number of flies caught on red boards $(10 \mathrm{~cm} . \times 30$ cm.) coated with "Tanglefoot," a sticky resin-base substance. Six of these "sticky boards" were suspended in each cage $(1.2 \mathrm{~m} . \times 1.2 \mathrm{~m} . \times 0.6 \mathrm{~m}$. height $)$ placed over the manure.

In the experiment on intact calf pen manure, 6 squares of sheet metal $1.2 \mathrm{~m}$. long on a side and $0.5 \mathrm{~m}$. high were sunk into the manure to a depth of about $20 \mathrm{~cm}$. and a strip of "Tanglefoot" $8 \mathrm{~cm}$. wide was applied around the outside. A screen cage rested on top of the manure inside the metal barrier.

Three of the enclosed areas were sprinkled with $4 \mathrm{l}$. of $0.5 \%$ Kelthane $^{\circledR}$ (1,1-bis ( $p$-chlorophenyl)-2,2,2-trichloroethanol) emulsion to destroy existing mites while the remaining areas were sprinkled with 4 liters of water. Three days later the mites were extracted by a modified Tullgren funnel from a 4-liter sample from each area. From each of the Kelthane-treated areas only 1 adult female $M$. muscaedomesticae was recovered. The samples from the water-treated areas yielded the following adult mites, respectively: 37,47 , and 45 female $M$. muscaedomesticae; 19,89 , and 40 female $M$. medarius; 136,41 , and 122 Parasitidae of both sexes. To each area 20,000 house fly eggs were added 3 days after Kelthane treatment. The emerged flies caught on the "sticky boards" were counted 26 days later.

In the outdoor experiment, 12 piles (1 m. diameter $\times 0.4 \mathrm{~m}$. height) of dairy cattle manure known to be heavily infested with macrochelids were made during July 1960. Six of the piles were sprinkled with 81 . of $0.5 \%$ Kelthane to destroy the mites and the remaining piles with $8 \mathrm{l}$. of water. Three replications each composed of 4 piles ( 2 with mites present and 2 with mites absent) were made at 10-day intervals. Tullgren funnel extractions of 4-liter samples from each pile taken 3 days after Kelthane treatment showed the mite eradication was successful (table 1). To each pile 50,000 house fly eggs were added 3 days after Kelthane treatment.

Studies With Introduced Mite Populations.-Three experiments were conducted indoors to determine the effect of known numbers of macrochelids in dairy cattle manure on the production of house flies. House fly production from eggs added to mite-free manure was compared to fly production from manure to which 200 adult female $M$. muscaedomesticae and 200 adult female $G$. confusa were added. These two species were the largest of those encountered and consequently most easily recognized. They were often found together in dairy cattle manure.

The mites were extracted by Tullgren funnels 2 or 3 days before use from manure in which the absence of species likely to be mistaken for these was determined by repeated sampling. The extracted mites were held in screen-topped jars with dairy cattle feces and provided fly eggs until the day used, when they were counted into 3-dram vials containing moist filter paper and transported to the site of the experiments.

Manure was obtained, when no more than 3 hours old, from the gutters of the Main Dairy Barn, Cornell University. The gutters were cleaned twice a day and repeated sampling established the absence of mites other than some Acaridae (Caloglyphus sp.). The manure was placed inside a heated barn $\left(18^{\circ}\right.$ to $2 \tau^{\circ} \mathrm{C}$.) on the solid bottom of screen cages resting on 15 -cm. legs coated with "Tanglefoot." Each cage $(60 \mathrm{~cm}$. square $\times 120 \mathrm{~cm}$. tall $)$ contained about 40 liters of manure and had 6 common fly ribbons suspended inside from the removable top to catch emerging flies.

The efficiency of the ribbons in catching flies was tested by placing 600 pupae and 6 ribbons in each of 5 cages. The number of unopened puparia (varied from 10 to 24 per cage) was subtracted from 600 to give the number of emerged flies per cage. The mean percentage of emerged flies caught on the ribbons was 86.9 with a standard deviation of 1.9 and a range of 83.8-88.3.

In the first indoor experiment, mites were added to 8 of the 12 cages of manure. No mites were added to the 4

Table 1.-Effect of Kelthane on mite population in outdoor piles of manure.

\begin{tabular}{|c|c|c|c|c|c|c|c|c|c|c|c|c|}
\hline \multirow[b]{4}{*}{ Mite Category } & \multicolumn{12}{|c|}{ Trentment $^{b}$} \\
\hline & \multicolumn{6}{|c|}{ Water } & \multicolumn{6}{|c|}{ Kelthane } \\
\hline & \multicolumn{2}{|c|}{ I } & \multicolumn{2}{|c|}{ II } & \multicolumn{2}{|c|}{ III } & \multicolumn{2}{|c|}{ I } & \multicolumn{2}{|c|}{ II } & \multicolumn{2}{|c|}{ III } \\
\hline & A & B & $\mathrm{A}$ & B & A & $\mathrm{B}$ & A & B & $\mathrm{A}$ & B & $\mathrm{A}$ & B \\
\hline M. muscaedomesticae & 336 & 209 & 25 & 102 & 2 & 3 & 4 & 0 & 4 & 8 & 0 & 0 \\
\hline M. medarius & 214 & 220 & 16 & 127 & 10 & 16 & 0 & 0 & 0 & 0 & 0 & 0 \\
\hline M. subbadius & 0 & 3 & 23 & 23 & 8 & 3 & 0 & 0 & 0 & 0 & 0 & 0 \\
\hline G. confusa & 3 & 5 & 35 & 80 & 24 & 37 & 0 & 0 & 1 & 0 & 0 & 0 \\
\hline Parasitidae & 14 & 3 & 97 & 10 & 0 & 0 & 0 & 0 & 3 & 0 & 0 & 0 \\
\hline Uropodidae & 0 & 1 & 0 & 0 & 9 & 11 & 0 & 0 & 0 & 0 & 0 & 0 \\
\hline Oribatidae & 0 & 0 & 0 & 0 & 0 & 1 & 0 & 0 & 0 & 0 & 0 & 0 \\
\hline
\end{tabular}

For the four species of Macrochelidae, only female adults were counted. For the other families, adults of both sexes were counted.

$\mathrm{b}$ The letters $\mathrm{A}$ and $\mathrm{B}$ designate piles; the numbers I, II, and III designate replicates. 
control cages. After a period of 12 hours, 20,000 house fly eggs were added to each cage during a four day period: 10,000 on the first day, 5,000 on the third day, and 5,000 on the fourth day. The house flies adhering to the ribbons were counted after emergence was completed 21 days later.

A second experiment was immediately conducted by adding fresh manure on top of the old mold-and-miteinfested manure in each cage. No further additions of macrochelids were made. The same control cages as in the first experiment were used again as controls and 20,000 eggs were added to each. Four of the caged piles with macrochelids present received 20,000 eggs and the remaining 4 received 60,000 eggs.

The third experiment was conducted after the cages were cleaned with steam and hot water. Fresh manure was added to all cages and adult female mites (200 M. muscaedomesticae and $200 \mathrm{G}$. confusa) were added to half of the cages. Six caged piles of manure containing mites received a total of 60,000 house fly eggs in two ways: (1) single dose and (2) multiple dose. In the former, all eggs were added on the first day. In the latter, 30,000 eggs were added on the first day, 15,000 on the third day and 15,000 on the fourth day. Six caged piles without mites received a total of 20,000 eggs in the same ways. With the single dose, 20,000 eggs were added on the first day. With the multiple dose, 10,000 eggs were added on the first day, 5,000 on the third day, and 5,000 on the fourth day. It was necessary to use this lower number of eggs in these cages without mites to be able to count the flies on the ribbons. The actual number of flies recovered from the 20,000 eggs was multiplied by 3 to obtain the number of flies expected from 60,000 eggs. Since sufficient eggs were not available to start all replicates on the same day, replicates I and II were initiated on September 11, and replicate III on September 12, 1961.

Concurrent with egg additions to the manure in the third experiment, aliquots of 2,000 eggs each were transferred to CSMA medium in 2 -liter containers held at $27^{\circ}$ $\pm 2^{\circ} \mathrm{C}$. to determine the potential yield of flies.

Results.-Effect of Existing Mite Populations.-With the naturally occurring mite population present, significantly fewer flies were produced from the intact calf pen manure than from the manure with the mites destroyed (table 2). Although the number of flies produced varied considerably among replicates, the reduction in numbers of flies per replicate varied only from $61 \%$ to $67 \%$.

As shown in table 3, fly production from outdoor ma-

Table 2.-Effect of mite population on house fly production from 20,000 eggs added to intact calf pen manure.

\begin{tabular}{|c|c|c|c|c|}
\hline \multirow[b]{2}{*}{ Treatment } & \multicolumn{4}{|c|}{ Number of Flies per Replicate } \\
\hline & I & II & III & Mean \\
\hline Mites present & 18 & 25 & 42 & 28 \\
\hline Mites absent ${ }^{\mathrm{a}}$ & 55 & 65 & 128 & 83 \\
\hline Analysis of variance: & & $M S$ & $F$ & \\
\hline Treatments & df & $\begin{array}{l}115 \\
4428\end{array}$ & $11.7^{\mathrm{b}}$ & \\
\hline Replicates & 2 & 1341 & 3.5 & \\
\hline Error & 2 & 877 & & \\
\hline
\end{tabular}

A Manure treated with Kelthane.

b Significant at $10 \%$ probability level.
Table 3.-Effect of mite population on production of house flies from 50,000 eggs added to outdoor piles of manure.

\begin{tabular}{|c|c|c|c|c|c|c|c|}
\hline \multirow[b]{3}{*}{ Treatment } & \multicolumn{7}{|c|}{ Number of Flife per Pile per Replicate } \\
\hline & \multicolumn{2}{|c|}{ I } & \multicolumn{2}{|c|}{ II } & \multicolumn{2}{|c|}{ III } & \multirow[b]{2}{*}{ Mean } \\
\hline & A & $\mathrm{B}$ & A & B & A & B & \\
\hline Mites present & 147 & 309 & 99 & $\gamma_{1}$ & 70 & 52 & 125 \\
\hline Mites absent ${ }^{\mathrm{a}}$ & 406 & 421 & 184 & 127 & 123 & 54 & 219 \\
\hline \multicolumn{8}{|l|}{ Analysis of variance: } \\
\hline & \multirow{2}{*}{\multicolumn{2}{|c|}{$d_{j}$}} & \multirow{2}{*}{\multicolumn{2}{|c|}{$\begin{array}{c}M S \\
26790\end{array}$}} & & \multirow{2}{*}{\multicolumn{2}{|c|}{$\begin{array}{l}F \\
9.0^{\mathrm{b}}\end{array}$}} \\
\hline $\begin{array}{l}\text { Treatments } \\
\text { Replicates }\end{array}$ & & & & & & & \\
\hline $\begin{array}{l}\text { Replicates } \\
\text { Interaction }\end{array}$ & \multicolumn{2}{|c|}{2} & \multicolumn{2}{|c|}{68524} & & \multicolumn{2}{|c|}{$23.1^{\mathrm{c}}$} \\
\hline $\begin{array}{l}\text { Interaction } \\
\text { Error }\end{array}$ & \multirow{2}{*}{\multicolumn{2}{|c|}{$\underset{2}{2}$}} & \multirow{2}{*}{\multicolumn{2}{|c|}{$\begin{array}{r}6673 \\
2965\end{array}$}} & & \multirow{2}{*}{\multicolumn{2}{|c|}{2.2}} \\
\hline Error & & & & & & & \\
\hline
\end{tabular}

Manure treated with Kelthane.

b Significant at $5 \%$ probability level.

$\circ$ Significant at $1 \%$ probability level.

nure piles with mites present was significantly less than from piles with the mites destroyed. The reductions per replicate varied from $31 \%$ to $45 \%$. Due to the effects of weathering and rain, it was difficult to distinguish house flies from other similar flies on the "sticky boards." Hence the flies counted were largely house flies, but not exclusively.

Effect of Introduced Mite Populations.-In all 3 indoor experiments with known numbers of $M$. muscaedomesticae and $G$. confusa, fewer house flies were produced in the presence of these mites than in their absence. House fly production from 20,000 eggs was reduced drastically by the mites in the first experiment (table 4). The reductions per replicate varied from $86 \%$ to $98 \%$ with a mean of $94 \%$.

The results of the second indoor experiment are given in table 5. The differences in fly production in the presence and absence of mites were highly significant. The differences in actual numbers of flies produced from 60,000 and 20,000 eggs in the presence of mites were not significant (Tukey's test). No data were available to show the number of eggs that would have caused a significant increase in actual numbers of flies. In this experiment, some reproduction of the mites might have occurred so that the numbers of macrochelids in each pile were no longer known, but they should have been very similar since the same number were added initially and all piles previously received the same number of fly eggs.

The results of the third experiment, to determine the effect on mite predation of two ways of adding eggs, are presented in table 6 . There were significant differences in

Table 4.-Effect of $200 \mathrm{M}$. muscaedomesticae and 200 $G$. confusa on house fly production from 20,000 eggs added to indoor piles of manure.

\begin{tabular}{|c|c|c|c|c|c|c|}
\hline \multirow[b]{2}{*}{ Treatment } & \multirow[b]{2}{*}{ Pile } & \multicolumn{5}{|c|}{ Number of Flifs per Replicate } \\
\hline & & I & II & III & IV & Mean \\
\hline \multirow{2}{*}{$\overline{\text { Mites present }}$} & $\mathrm{A}$ & 256 & 176 & 101 & 58 & 148 \\
\hline & B & 134 & 382 & 127 & 173 & 204 \\
\hline Mites absent & A & 2449 & 2713 & 2697 & 3849 & 2927 \\
\hline \multicolumn{7}{|l|}{ Analysis of variance: } \\
\hline Treatments & df & & $\begin{array}{c}M S \\
20183170\end{array}$ & & 2267 & \\
\hline Replicates & 3 & & 106791 & & & \\
\hline Interaction & 3 & & 298006 & & & \\
\hline Error & 4 & & 8902 & & & \\
\hline
\end{tabular}

- Significant at $1 \%$ probability level.

b Significant at $5 \%$ probability level. 
Table 5.-Effect of $M$. muscaedomesticae and $G$. confusa on house fly production from two different quantities of eggs added to indoor piles of manure.

\begin{tabular}{|c|c|c|c|c|c|c|}
\hline \multirow[b]{2}{*}{ Treatment } & \multirow{2}{*}{$\begin{array}{l}\text { Number } \\
\text { OF EgGs }\end{array}$} & \multicolumn{5}{|c|}{ Number of Flies per Replicate } \\
\hline & & I & II & III & IV & Mean \\
\hline Mites present & 60,000 & 13 & 10 & $q$ & 203 & 57 \\
\hline Mites present & 20,000 & 82 & 78 & 16 & 218 & 98 \\
\hline Mites absent & 20,000 & 1067 & 878 & 2687 & 1955 & 1647 \\
\hline \multicolumn{7}{|c|}{ Analysis of variance: } \\
\hline & \multirow{2}{*}{\multicolumn{2}{|c|}{$\underset{\mathcal{Z}}{d f}$}} & \multirow{2}{*}{\multicolumn{2}{|c|}{$\begin{array}{c}M S \\
8984070\end{array}$}} & \multirow{2}{*}{\multicolumn{2}{|c|}{$\stackrel{F}{F}$}} \\
\hline $\begin{array}{l}\text { Treatments } \\
\text { Replicates }\end{array}$ & & & \multirow{2}{*}{\multicolumn{2}{|c|}{$\begin{array}{r}3284070 \\
250375\end{array}$}} & & \\
\hline $\begin{array}{l}\text { Replicates } \\
\text { Error }\end{array}$ & 8 & & & & \multicolumn{2}{|c|}{1.1} \\
\hline Error & 6 & & \multicolumn{2}{|c|}{238893} & & \\
\hline
\end{tabular}

a Significant at $1 \%$ probability level. The differences in fly production from the two egg levels in the presence of mites were not significant (Tukey's Test).

fly production between egg doses and between the presence and absence of mites. As indicated by the significant interaction, the differences in fly production between the presence and the absence of mites differed for the two egg doses. The simple effects were examined by one-degree-offreedom comparisons of the four possible treatment combinations as shown in the auxiliary table. With the eggs added in a single dose, significantly fewer flies were produced in the presence of the mites. Addition of the eggs in a multiple dose allowed greater feeding time, but the presence of the mites did not cause a significantly lower fly production. In the presence of mites, the differences in fly production between egg doses were not significant. With mites absent, the differences in fly production between egg doses were highly significant. The lower fly production from the multiple egg dose was probably due to the aging of the manure and differences in the hatching of the eggs used on successive days.

Although the mites caused an appreciable reduction in house fly production in this experiment, there were other factors causing even more drastic reduction. The yield of flies from CSMA medium from aliquots of the eggs added in a single dose was $69 \%$ for replicates I and II, and $54 \%$ for replicate III. The same yields apply to the portions of the multiple dose added on the first day, while the portions added on the third and fourth days had yields of $71 \%$ and $55 \%$, respectively. Therefore, the 60,000 eggs added to the mite-infested manure in a single dose had the potential of producing 32,490 to 41,490 flies. The actual fly production (table 6 ) was 931 to 1076 , a $97 \%$ mean reduction compared to the potential production. Likewise, the 20,000 eggs added to the mite-free manure had the potential of producing 10,830 to 13,830 flies. The actual fly production (1700 to 2853 ) was an $83 \%$ mean reduction compared to the potential production. Thus, the per cent reduction increased by 14 when mites were present. Similar calculations may be made for the multiple dose. With the multiple egg dose, the per cent reductions obtained by comparing the fly production from manure to that from CSMA medium were also large (92\% without mites and $96 \%$ with mites). The presence of the mites resulted in an increase of 4 in the per cent reduction. According to the single-degree-of-freedom comparison, this was not significant.

Further substantiation of low fly production from dairy cattle manure was obtained by adding house fly eggs to manure held in $20 \mathrm{l}$. cans. Of the $50,000 \mathrm{eggs}$ added to each of three cans, $3.4 \%, 5.8 \%$, and $5.3 \%$ yielded adult flies. Concurrent yields of flies from 2,500 eggs added to each of four 2-liter cans containing CSMA medium were from $52.5 \%$ to $62.0 \%$.

Discussion.- The reductions in house fly production from the calf pen manure were reflections of the Macrochelidae present, but should not be considered completely due to them since large numbers of Parasitidae were present. Parasitids were observed in the laboratory to accept fly eggs as food and their predation should be investigated further. The reductions in fly production from outdoor piles of manure were associated with the presence of Macrochelidae, but perhaps were also partially due to the small numbers of Parasitidae present.

M. muscaedomesticae and G. confusa drastically reduced house fly production from the indoor caged manure. It was not determined how many eggs would be needed to deluge the mites to such an extent that their predation effect would not be significant. Certainly this would be considerably more than $20,000 \mathrm{eggs}$, since at that level the 400 introduced mites gave $86 \%$ to $98 \%$ reductions in fly production. In the second experiment the molds and acarid mites present were possible alternate foods for the macrochelids, but very high reductions in fly production at the two egg levels were produced by the macrochelids. This suggests a preference for fly eggs and larvae by macrochelids, but this needs to be substantiated by further studies. M. muscaedomestiae were observed to feed on soft-bodied acarid mites in the laboratory.

In all experiments, the numbers of flies recovered from several thousand eggs were small, whether mites were present or absent. The actual numbers of flies recovered from the manure were much less than the equivalent numbers from CSMA medium. The small numbers of flies produced from the manure were not caused by adding eggs that were incapable of becoming adult flies, but were caused by properties associated with the manure. The reductions in numbers of flies by macrochelids were large when actual fly production from manure was considered, but were small compared to the potential number of flies which the eggs could produce. Factors other than macro-

Table 6.-Effect of two methods of adding a total of 60,000 house fly eggs to indoor piles of manure on the reduction in number of flies by 200 M. muscaedomesticae and 200 G. confusa.

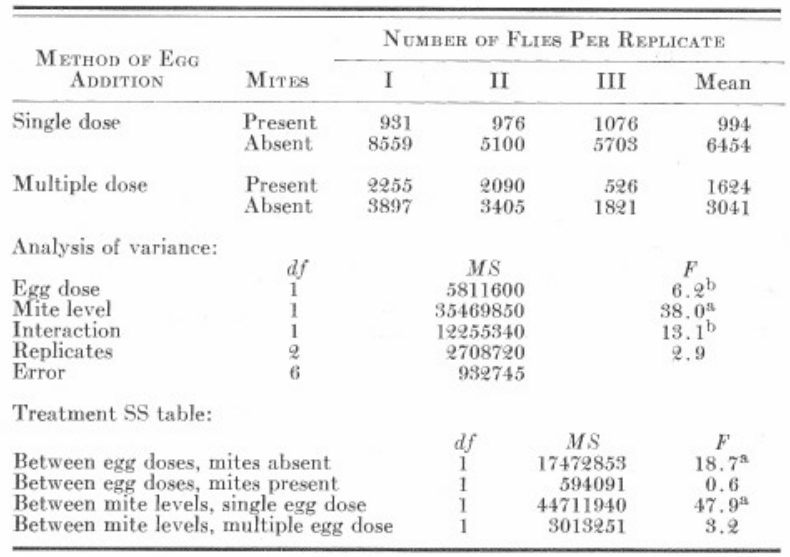

a Significant at $1 \%$ probability level.

b Significant at $5 \%$ probability level. 
chelids accounted for the major portion of the differences between actual and potential fly production from manure. These factors have not been investigated.

The combined use of chemical and biological agents to control house flies breeding in manure seems sufficiently promising to deserve further investigation. When cords and baits are used for adult fly control, the manure is not contaminated by the toxicants and the mites provide concurrent fly control by predation on the eggs and larvae. It is likely that currently recommended chemicals for house fly control cause considerable mite mortality from manure contamination during residual spray applications and from larvicide treatments of the manure, but this has not been substantiated. Although house fly control would be more effective if chemicals toxic to the fly but harmless to the mites were used, such chemicals have not been identified.

\section{References Cited}

Axtell, R. C. 1961. New records of North American Macro- chelidae (Acarina: Mesostigmata) and their predation rates on the house fly. Ann. Ent. Soc. Amer. 54(5); 748 .

Filipponi, A. 1955. Sulla natura dell'associazione tra Macrocheles muscaedomesticae e Musca domestica. Riv. Parasitol. 16(2): 83-102.

Pereira, C., and M. P. de Castro. 1945. Contribuição para o conhecimento da espécie tipo de "Macrocheles Latr." ("Acarina"): "M. muscaedomesticae (Scopoli, 1772)" emend. Arch. Inst. Biol. 16: 153-86.

Pereira, C., and M. P. de Castro. 1947. Forese e partenogenese arrenotoca em "Macrocheles muscaedomesticae" (Scopoli) ("Acarina: Macrochelidae") e sua significação ecologica. Arch. Inst. Biol. 18: 71-89.

Rodriguez, J. G., and C. F. Wade. 1961. The nutrition of Macrocheles muscaedomesticae (Acarina: Macrochelidae) in relation to its predatory action on the house fly egg. Ann. Ent. Soc. Amer. 54(6): 782-8.

Wade, C. F., and J. G. Rodriguez. 1961. Life history of Macrocheles muscaedomesticae (Acarina: Macrochelidae), a predator of the house fly. Ann. Ent. Soc. Amer. 54(6): 776-81.

Reprinted from the JotrRALL of ECONOMIC ENTOMOLOGY

Vol. 56, No. 3, June, 1963 pp. $317-321$ 